\title{
Cross-Border Mergers and Greenfield Foreign Direct Investment
}

\author{
Ignat Stepanok \\ Kiel Institute for the World Economy
}

October 16, 2013

\begin{abstract}
I present a model of international trade and foreign direct investment (FDI), where FDI is comprised of greenfield FDI and mergers and acquisitions (M\&A). Working in a monopolistically competitive environment, merging firms do not reduce competition. Mergers are motivated by efficiency gains and transfer of technology and expertise. Following empirical evidence, I model greenfield investors as the more productive group relative to M\&A firms, which are in turn more productive than exporters. The model has two symmetric countries and generates two-way flows of both M\&A and greenfield FDI. Greater proximity to a market makes more firms choose greenfield FDI over M\&A when investing there. Empirical evidence supports this result.
\end{abstract}

Keywords: Foreign direct investment, mergers, acquisitions, greenfield, firm heterogeneity. JEL classification: F12; F23.

Acknowledgments: I thank Paul Segerstrom for his advice and thorough discussion of the paper. I am also grateful to David Domeij, Frédéric Robert-Nicoud and Yoichi Sugita for useful comments and suggestions as well as participants at the European Trade Study Group meeting in Copenhagen, the Spring Meeting of Young Economists in Mannheim and seminar participants at the Kiel Institute for the World Economy. Financial support from the Wallander Foundation and the Fritz Thyssen Foundation is gratefully acknowledged.

Author: Ignat Stepanok, Kiel Institute for the World Economy, Hindenburgufer 66, D24105 Kiel, Germany ignat.stepanok@ifw-kiel.de

\section{Introduction}

This paper presents a model of foreign direct investment (FDI) that consists of both greenfield FDI (building of a production facility abroad) and mergers and acquisitions (M\&A). Most of the horizontal FDI literature describes FDI as greenfield FDI. It explores the trade-off between the benefit of economies of scale of producing at home versus the benefit of producing 
abroad and foregoing the payment of the variable costs of trade like transportation costs and tariffs. The bulk of FDI however belongs to cross-border M\&A activity, over eighty percent in 1999 according to UNCTAD (2000), or according to Head and Ries (2008) for the years between 1987 and 2001 two thirds of total FDI.

When looking at total M\&A activity, cross-border and domestic deals, cross-border activity also constitutes a significant share. According to Gugler et. al. (2003) for the period 1981-1998, cross-border mergers as a share of all mergers were $10.6 \%$ in the US, $29.9 \%$ in the UK, $33.5 \%$ in continental Europe, $52.6 \%$ in Japan, $30.0 \%$ in Australia, New Zealand and Canada and $28.5 \%$ in the rest of the world.

In order to study the effect of policy on FDI, it is important to properly model its composition and firms' incentives to chose a particular mode of entry into foreign markets. The purpose of this paper is to model FDI not only as greenfield investment but also as cross-border M\&A. The paper does not investigate domestic M\&A activity.

In the literature on FDI composition and trade, mergers are modelled in an oligopolistic setting as in Neary (2009), where the incentive to merge is based on strategic motives (merging firms reduce competition), exploiting complementarities among merging parties (firm headquarters with a specific entrepreneurial ability and a production facility with a separate productivity) in a monopolistically competitive market as in Nocke and Yeaple (2007) and (2008) or in an oligopolistic market as in Norbäck and Persson (2007) and (2008). The current model suggests a different incentive for firms to merge: transfer of technology and managerial expertise from the more productive firm to the less productive one. There are three empirical regularities related to FDI that the model fits: first, greenfield investors are more productive than M\&A firms. Second, the model generates two-way flows of both M\&A and greenfield FDI. Third, the closer are the two countries, the more greenfield FDI is chosen over M\&A as a mode of entry.

I build a model with heterogeneous productivities as in Melitz (2003). There are two symmetric economies Home and Foreign. When a firm is "born" it draws a marginal cost from an exogenous distribution. Depending on how productive it turns out to be, it has several options to choose from: (i) to not enter any market, (ii) to enter only its local market, (iii) to enter its local market and to export to Foreign, (iv) to enter its local market and to merge with (take over) a firm abroad, or (v) to enter its local market and to invest in a new plant in Foreign that will allow it to produce its product abroad. Each of those choices are optimal depending on where on the productivity distribution a firm is. I solve the model for an equilibrium where the least productive firms choose (i), the more productive choose (ii), ... and the most productive choose option (v).

This ordering is certainly not arbitrary. Empirical evidence shows that exporters are more productive than non-exporters (see Bernard and Jensen (1999), Aw, Chung and Roberts (2000) and Clerides, Lach and Tybout (1998)), firms engaging in FDI are in turn more productive than exporting firms (see Girma, Kneller and Pisu (2005), Helpman (2006)) and within the group of firms choosing FDI as an option for entering the foreign market, the more productive ones are involved in greenfield FDI (see Nocke and Yeaple (2008)). The ordering is also supported by Raff et. al. (2011) who look at Japanese firm-level data.

In line with the theoretical literature on trade and firms with heterogenous productivities (in particular Melitz (2003) and Helpman, Melitz and Yeaple (2004)), I connect the choice to enter a market, both local and foreign, with a one-time payment of a fixed cost. The 
magnitude of the fixed costs determines the productivity necessary to enter or not and if yes how (choices (i) through (v)). Helpman, Melitz and Yeaple (2004) have in addition to the usual fixed costs for entering the local market and for exporting a third one. This is the fixed cost for building a plant abroad. The innovative aspect of this paper is to introduce one more fixed cost: for merging with a foreign firm. Once the merger is completed, the home investor can use the production facilities of the foreign firm. A home firm can therefore enter the foreign market in one of three ways, by exporting, by merging with (acquiring) a foreign firm or by building a plant there.

Home firms find it optimal to acquire failing foreign firms since the benefit from the knowledge transfer in that case is greatest. The acquirer pays the fixed cost for the merger and is randomly assigned to a failing firm. The new restructured plant has a productivity inbetween the productivities of the two merging entities. The benefit from the merger is split according to a Nash bargaining solution.

When Renault took a third ownership in Nissan in 1999, it installed one of its top managers, Carlos Ghosn, as Nissan's CEO. He restructured Nissan and brought it back to profitability. It is this transfer of expertise and technology that I model. According to Bloom and Van Reenen (2010) management practices are an important source of firm productivity, where firms with better management are more productive and larger.

In comparison to Melitz (2003), in my model there are two more productivity thresholds, one that separates exporters from firms involved in M\&A and the other the threshold dividing firms involved in M\&A and firms that open their own factory abroad (greenfield FDI). Lower variable costs to trade reduce total FDI mostly at the expense of M\&A firms, which in turn results in a higher share of greenfield investment in total FDI.

The contribution of the model developed in this paper is twofold: first, both greenfield FDI and cross-border M\&A exist simultaneously and go both ways from Home to Foreign and from Foreign to Home. This is not present in Nocke and Yeaple (2008), which is the model closest to mine when it comes to the results on FDI composition it generates. In their model of asymmetric countries, M\&A flows both ways. Greenfield FDI however goes only from the richer to the poorer country, while as income differences between the two countries become smaller, greenfield FDI decreases. Given their setup, there would be no greenfield FDI between equally developed economies, which is clearly at odds with the evidence.

Second, in the current model greater proximity to the foreign market increases the share of greenfield FDI. In order to generate this result, Nocke and Yeaple (2008) assume that the fixed cost for opening up a factory abroad is lower, the smaller the distance to the foreign country. Given that my model has iceberg trade costs (not present in Nocke and Yeaple (2008)), I believe that it generates that particular result in a more natural way, thinking of distance as affecting variable rather than fixed costs.

The next section lays out the model. Section three gives the solution and section four discusses the results. There is also an appendix where the more involving calculations are spelled out. 


\section{The Model}

In the model there are two symmetric economies (countries) Home and Foreign, a single consumption good sector with Dixit-Stiglitz monopolistic competition. The size of population in each country is exogenous and does not grow. Labor is the single factor of production, the labor market is perfectly competitive and there is no unemployment. Each worker is endowed with one unit of labor, which is inelastically supplied. Firms invest to discover new varieties of products. This investment represents a one-time product development fixed cost. After the firm incurs that cost and discovers a product, it draws its marginal cost from a given distribution.

To enter the Home and Foreign markets, there are certain exogenously given fixed costs to be paid, all of them paid in terms of labor units. Every choice of entry is associated with the payment of a fixed cost while exporters in addition face iceberg trade costs when shipping goods to the foreign market. Instead of exporting, a firm can choose to take over a foreign firm and use its production facilities. The benefit for the acquiring firm is not only to be able to gain a foothold for its product on the other market, but it also transfers part of its productivity to the less productive foreign firm. Some firms choose instead of exporting or taking over a foreign firm to establish their own plant abroad.

\subsection{Consumers}

The representative consumer has a CES utility function given by

$$
u \equiv\left(\int_{0}^{m^{c}} x(\omega)^{\alpha} d \omega\right)^{\frac{1}{\alpha}}
$$

where $m^{c}$ is the measure of varieties available in the Home market, $x(\omega)$ is the amount an individual consumes of a particular variety $\omega$ and the degree of differentiation between products is determined by $\alpha \in(0,1)$. Products are gross substitutes with an elasticity of substitution $\sigma \equiv 1 /(1-\alpha)>1$.

Solving the optimization problem gives the following demand function:

$$
x(\omega)=\frac{p(\omega)^{-\sigma}}{P^{1-\sigma}} c
$$

where $P \equiv\left(\int_{0}^{m^{c}} p(\omega)^{1-\sigma} d \omega\right)^{\frac{1}{1-\sigma}}$ is an aggregate price index, $c$ is individual expenditure and $p(\omega)$ is the price of product $\omega$.

\subsection{Producers}

To create a new product variety, a firm needs to pay a fixed cost equal to $F_{I}$ labor units. After the invention of a new variety, the firm draws a marginal cost parameter which indicates how many labor units it takes to produce a unit of the good. The marginal cost parameter is drawn from a Pareto distribution which has a probability density function $g(a)$ with support $[0, \bar{a}]$ and a cumulative density function $G(a)=\int_{0}^{a} g(a) d a=(a / \bar{a})^{k}$. Melitz (2003) works 
with a general distribution, Helpman, Melitz and Yeaple (2004) show that the model becomes much more tractable if one chooses a Pareto distribution. The empirical literature on the size distribution of firms suggests that this is a reasonable choice (see Del Gatto, Mion and Ottaviano (2006)).

The model will generate several marginal cost thresholds which determine whether a firm enters a market or not and if it does, how, by exporting, by acquiring a firm abroad or by building a new plant. I use at some places throughout the text productivity instead of marginal cost, keeping in mind that low marginal cost corresponds to high productivity.

Given a particular marginal cost draw $a(\omega)$ for producing the new variety $\omega$, a firm makes the following profits selling in its local market:

$$
\pi_{L}=\max _{p_{L}}\left(p_{L}-a(\omega)\right) x_{L}(\omega)
$$

where $p_{L}$ is the price a firm holding the patent for product variety $\omega$ sets on its local market and $x_{L}(\omega)$ is demand for that locally manufactured product. Using (1) and $C \equiv c L$ as aggregate expenditure, I obtain that the optimal price is $p_{L}(\omega)=\frac{\sigma}{\sigma-1} a(\omega)$ and local profits are

$$
\pi_{L}=\delta\left(\frac{a(\omega)}{P}\right)^{1-\sigma} C,
$$

where $\delta \equiv(\sigma-1)^{\sigma-1} \sigma^{-\sigma}$.

A firm makes the following profits selling in its export market:

$$
\pi_{E}=\max _{p_{E}}\left(p_{E}-\tau a(\omega)\right) x_{E}(\omega),
$$

where $\tau>1$ is an iceberg variable cost to trade and $x_{E}(\omega)$ is demand for an exported product $\omega$. Optimization yields $p_{E}(\omega)=\frac{\sigma}{\sigma-1} \tau a(\omega)$ and exporting profits are

$$
\pi_{E}=\delta\left(\frac{\tau a(\omega)}{P}\right)^{1-\sigma} C
$$

I can express the relation between profits from selling on the local market and from exporting as $\pi_{E}=\theta \pi_{L}$, where $\theta \equiv \tau^{1-\sigma}$. The case of autarky corresponds to $\theta=0$ and free trade to $\theta=1$.

\subsection{Value Equations and Marginal Cost Cutoffs}

There are four types of producing firms. The first type is those that sell only at home, their value will be denoted by $v_{L}(a)$. The second type is those that sell at home and export, with value $v_{L}(a)+v_{E}(a)$, where $v_{E}(a)$ is the value of the exporting section of a firm's operation. There also are firms that sell at home and have merged with a foreign firm. They have value $v_{L}(a)+v_{L}\left(a^{\prime}\right)$, where $a^{\prime}$ is the productivity of the foreign plant. The fourth type is those firms that sell at Home and have a subsidiary abroad. They have value $2 v_{L}(a)$, since they sell one product on two markets without paying any variable costs to trade and the subsidiary plant has the same productivity as the plant in Home. 
Each firm faces an exogenous exit probability equal to $\gamma$. The value of a home operation of a firm is therefore

$$
v_{L}(a)=\frac{\pi_{L}(a)}{\gamma}
$$

The value equation for the exporting section of a firm must equal

$$
v_{E}(a)=\frac{\pi_{E}(a)}{\gamma}
$$

From (3), (4) and $\pi_{E}=\theta \pi_{L}$, one can see that $v_{E}(a)=\theta v_{L}(a)$.

Let the value function from selling in the local market net of the fixed cost of entering the local market be $f_{L}(a) \equiv v_{L}(a)-F_{L}$. Let the marginal cost below which firms find it optimal to enter their local market be $a_{L}$. Firms with marginal cost draws of $a \in\left(a_{L}, \bar{a}\right)$ will not be able to cover the fixed cost for entering the local market $F_{L}$ and will therefore not enter. The value of the firm with the threshold marginal cost net of the fixed cost to entering the local market must equal the value of a failing firm for now written $v_{F}$ :

$$
f_{L}\left(a_{L}\right)=v_{F}
$$

The way the the value of the failing firm is written, it is independent of its marginal cost draw. This follows directly from the M\&A technology introduced below.

\subsubsection{Mergers and Acquisitions}

The industrial organization literature has emphasized two main motives for a merger: efficiency gains and strategic motives. By strategic motives one has in mind reducing competition in a market where firms are not atomistic and affect the behavior of others. In my model with monopolistic competition, each firm is infinitely small and its merger with another firm does not affect the behavior of other firms. Without dismissing the importance of strategic interactions between firms in oligopolistic markets, I focus my attention on efficiency gains through transfer of knowledge and study this as one of the possible channels through which variable costs to trade can affect the composition of FDI.

There are several assumptions that I make regarding the M\&A process. The first one is that the acquiring firm pays a fixed cost to initiate a merger. The fixed cost can be seen

as a fee for a consultant to evaluate and facilitate the merger, the cost of restructuring the foreign enterprise and facilitating its entry in the foreign market.

Let $a_{h}$ be the marginal cost of a home firm that acquires a foreign target. The restructured foreign enterprise will have a marginal cost

$$
a^{\prime} \equiv z a_{h},
$$

where $z>1$. This restructuring technology has the desirable property that $a^{\prime}$ is an increasing function of $a_{h}$. It is a simplifying assumption to not tie $a^{\prime}$ to the marginal cost of the target firm. A possible extension could be to use a Cobb-Douglas technology, where $a^{\prime}$ would depend positively on both $a_{h}$ and the marginal cost of the target firm $a_{f}$.

The third assumption I make is that one plant can produce only one product. The marginal cost draw of a plant is tied to the product and that can not be improved. In case of a merger 
the new enterprise can either produce the old product of the foreign firm with a marginal cost $a^{\prime}=a_{f}$ or produce the product of the acquirer with a marginal cost $z a_{h}>a_{h}$. Firms therefore do not sell more than one product. This simplification focuses the attention on that aspect of cross-border mergers that deals with the combined incentive of gaining foothold in a foreign market and transfer of knowledge/technology to a foreign plant in order to make it more productive.

The acquiring firm can merge with any foreign firm, including failing firms. If the acquired firm is sufficiently more productive than the acquirer so that $a_{f} \leq a^{\prime}$, then the acquired firm's product will be kept. There would be no transfer of knowledge to the new bought enterprise nor would it facilitate the acquirer to gain foothold in the foreign country. There would be no benefit, but there would be the cost for the merger. If the acquired firm is sufficiently less productive than the acquirer however (to be precise, less productive than the potential restructured plant, $a_{f}>a^{\prime}$ ) then there will be a gain from the transfer of knowledge and the product of the acquired firm will be divested. The product of the acquirer will be produced. Given however that $a^{\prime}$ does not depend on $a_{f}$, it would be optimal from the point of view of the acquirer to merge with a firm that has the lowest productivity, or highest marginal cost, since in that case the loss from the divested product would be lowest. It follows that the acquiring firm would target only failing foreign firms, provided that there is a sufficient number of failing firms.

A sufficient number of failing firms would mean that the number of acquiring firms is smaller than the number of target firms, thus every firm that wishes to take over another firm abroad can find a failing firm to do so. I solve for an equilibrium where this holds.

Let a failing firm have marginal cost $a_{f} \in\left(a_{L}, \bar{a}\right)$. The restructured plant will have a marginal cost between the marginal costs of the acquiring and acquired firms $a_{h}<a^{\prime}<a_{f}$ if $a_{h}<z a_{L}$ for all $a_{h}$. I solve for an equilibrium where the last inequality holds.

A great number of firm mergers in Eastern Europe in the 1990s were negotiated to save failing state enterprises. As part of a privatization process, the governments were looking for foreign investors, which had the capability to increase those failing firms' productivities and to save them from bankruptcy. It is true that not only failing firms are being targeted in the M\&A market. In my setup the failing firms can also be described as plants with low productivity that belong to larger firms consisting of several plants, each with its own unique productivity. In this case mergers could be seen as a part of the process of firms buying and selling corporate assets. The main point is that a less competitive enterprise is being bought and restructured through which process it acquires a higher productivity. ${ }^{1}$

I should reiterate that this monopolistically competitive setup abstracts from any strategic gains from a merger, which very well might present an incentive to merge with firms

\footnotetext{
${ }^{1}$ In a study of M\&A activity in Canada and the US around the time of the Canada-United States Free Trade Agreement from 1989, Breinlich (2008) finds that acquiring firms are bigger, more productive and more profitable in comparison to target firms.

The empirical literature does report gains from mergers. Jensen (1988) cites empirical evidence from the M\&A literature, that takeovers "generate substantial gains: historically, eight percent of the total value of both companies." The gains are not redistribution from one firm to another, but rather improved efficiency. Mandelker (1974) finds evidence that mergers can be seen as a mechanism through which the market replaces incompetent management, thus increasing efficiency. Conyon et. al. (2002) find that firms that are acquired by foreign companies show an increase in labor productivity of $13 \%$.
} 
that are above the entry threshold productivity. There are setups where acquirers would cherry-pick local firms. I therefore do not claim to capture all possible gains or aspects of the cross-border M\&A activity. The gain from a merger in my model comes from two sources i) the acquired firm obtains a lower marginal cost of production: efficiency gains, can be seen as technology or knowledge transfer between firms ${ }^{2}$ ii) the acquiring firm gains a foothold in the foreign market for its product and uses the acquired firm's production plant abroad.

The last assumption I make on the M\&A process is that the gain from the merger is split between the acquiring and the target firm as a result of bargaining. Let the bargaining game be of the Rubinstein type (see Binmore et. al. (1986) for details). Both the acquiring and acquired firms do not have an immediate outside option. The value of the restructured enterprise will be $v_{L}\left(a^{\prime}\right)$. The Nash solution to the bargaining problem assigns a share $0<\psi<1$ of the gains from the merger to the acquiring firm and a share $1-\psi$ to the target firm, where the parameter $\psi$ represents the bargaining strength of the acquiring firm.

When a firm invests to merge with another firm abroad, it will pay the fixed cost $F_{M}$ and will be randomly assigned to a failing firm. The precise productivities of firms are not known when the investment $F_{M}$ is made. After the fixed cost for initiating the merger has been paid and firms have been matched, productivities are revealed and the two firms enter negotiations on how to split the proceeds from the merger.

\subsubsection{Entering the Foreign Market}

There are three ways a firm can enter the foreign market: through exporting, acquiring a foreign firm or building a plant abroad. Let the function $f_{E}(a) \equiv \theta v_{L}(a)-F_{E}$ represent the value of exporting net of the fixed cost of entering the export market, $f_{G}(a) \equiv v_{L}(a)-F_{G}$ represent the benefit of greenfield FDI net of the fixed cost of building a plant abroad and $f_{M}(a) \equiv \psi v_{L}\left(a^{\prime}\right)-F_{M}$ represent the benefit of a merger (a share $\psi$ goes to the acquirer) net of the fixed cost for initiating the merger.

Note that $v_{L}$ is proportional to $a^{1-\sigma}$. The functions $f_{E}, f_{M}$ and $f_{G}$ are all defined as functions of $a$ but when graphing these functions, it is convenient to think of them as functions of $a^{1-\sigma}$, since they are all upward-sloping and linear in $a^{1-\sigma}$. In all three functions, marginal cost $a$ enters only through the term $a^{1-\sigma}$, which can be seen as a measure of productivity (marginal cost raised to a negative power).

\footnotetext{
${ }^{2}$ In the theoretical M\&A literature some papers focus on modeling efficiency gains as reductions in marginal cost for the post-merger firm (see Werden (1996)). Roller et. al. (2006) provide a useful discussion and summary of the theoretical literature on the role of efficiencies in M\&A and how they are modeled. They discuss several different sources of efficiency gains and write that all can be modeled either as a reduction to variable or to fixed costs.
} 


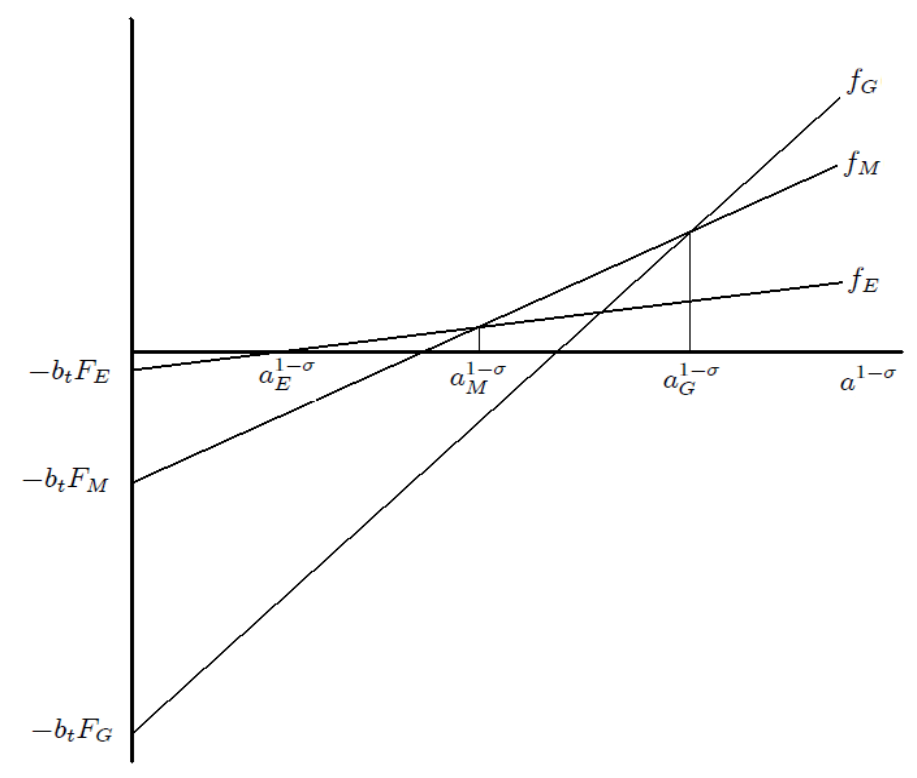

Figure 1.

The functions $f_{E}, f_{M}$ and $f_{G}$ are illustrated in Figure 1 and are drawn so that the firms with lowest marginal cost choose greenfield FDI $\left(a \in\left(0, a_{G}\right)\right.$ or $\left.a_{G}^{1-\sigma}<a^{1-\sigma}\right)$, firms with slightly higher marginal costs would rather acquire a foreign failing firm $\left(a \in\left(a_{G}, a_{M}\right)\right.$ or $\left.a_{M}^{1-\sigma}<a^{1-\sigma}<a_{G}^{1-\sigma}\right)$ and the least productive of firms entering the foreign market choose to export $\left(a \in\left(a_{M}, a_{E}\right)\right.$ or $\left.a_{E}^{1-\sigma}<a^{1-\sigma}<a_{M}^{1-\sigma}\right)$. This is not the only possible equilibrium for which one can solve, but it is the one I am interested in, in order to fit the empirical evidence on firm productivity and preferable mode of entry into foreign markets cited in the introduction.

For the ordering of outcomes illustrated in Figure 1 to occur, I need to assume that

$$
F_{E}<F_{M}<F_{G}
$$

Also the slope of $f_{G}$ must be steeper than that of $f_{M}$, which in turn must be steeper than that of $f_{E}$. For that to hold, I must have that

$$
\theta<\psi z^{1-\sigma}<1
$$

Firms with a new product before they draw a marginal cost are of mass $\dot{m} / G\left(a_{L}\right)$. Of those only $1-G\left(a_{L}\right)$ fail to enter their local market. Therefore the mass of all failing firms that have marginal cost $a \in\left(a_{L}, \bar{a}\right)$ (takeover targets) is $\dot{m}\left(1-G\left(a_{L}\right)\right) / G\left(a_{L}\right)$. The mass of all firms discovering a product that have marginal cost within the range $a \in\left(a_{G}, a_{M}\right)$ (looking for a takeover target) is $\dot{m}\left(G\left(a_{M}\right)-G\left(a_{G}\right)\right) / G\left(a_{L}\right)$. Therefore the probability of being taken over is $\epsilon \equiv \frac{G\left(a_{M}\right)-G\left(a_{G}\right)}{1-G\left(a_{L}\right)}$. When I solve for the equilibrium, I make sure that

$$
0<\epsilon<1
$$

holds. 
The value of a failing firm equals the likelihood with which that firm will become a takeover target times the share from the gains from a merger, times the expected gain. The expectation is taken with respect of $a_{h}$, since a failing firm does not know the marginal cost of a potential match:

$$
v_{F}=\epsilon(1-\psi) E\left[v_{L}\left(a^{\prime}\right)\right] .
$$

In order to find $a_{L}$ I go back to $f_{L}\left(a_{L}\right)=v_{L}\left(a_{L}\right)-F_{L}=v_{F}$. As shown in the appendix, substituting for the value function from (3) and then for profits from (2) yields

$$
a_{L}^{1-\sigma}=\frac{F_{L}}{1-(1-\psi) z^{1-\sigma} \varepsilon} \frac{\gamma}{\delta P^{\sigma-1} C},
$$

where

$$
\varepsilon \equiv \frac{\epsilon E\left[a_{h}^{1-\sigma}\right]}{a_{L}^{1-\sigma}}=\frac{k}{k-\sigma+1} \frac{\left(a_{M} / a_{L}\right)^{k-\sigma+1}-\left(a_{G} / a_{L}\right)^{k-\sigma+1}}{\left(\bar{a} / a_{L}\right)^{k}-1} .
$$

Strictly speaking $\varepsilon$ is the probability of a failing firm being taken over $\epsilon$, times the expected productivity of the potential acquirer $E\left[a_{h}^{1-\sigma}\right]$ divided by a measure of the productivity of a firm that is indifferent between entering its home market or not $a_{L}^{1-\sigma}$.

The value of the foreign operation of an exporter with the cutoff marginal cost for entering the foreign market (denoted by $a_{E}$ ) must be equal to the fixed cost that it needs to pay to enter $f_{E}\left(a_{E}\right)=\theta v_{L}\left(a_{E}\right)-F_{E}=0$, as in Melitz (2003). Substituting for the value function from (3) and for profits from (2) yields

$$
a_{E}^{1-\sigma}=\frac{F_{E}}{\theta} \frac{\gamma}{\delta P^{\sigma-1} C} .
$$

As illustrated in Figure 1, the value from entering through a merger is lower than from entering as an exporter for less productive firms $\left(a^{1-\sigma}<a_{M}^{1-\sigma}\right)$ but becomes preferable for more productive firms $\left(a^{1-\sigma}>a_{M}^{1-\sigma}\right)$. I define $a_{M}$ to be the marginal cost threshold where $f_{E}\left(a_{M}\right)=f_{M}\left(a_{M}\right)$. I substitute into this expression for the value functions and for profits from (2) and (3) to obtain

$$
a_{M}^{1-\sigma}=\frac{F_{M}-F_{E}}{\psi z^{1-\sigma}-\theta} \frac{\gamma}{\delta P^{\sigma-1} C} .
$$

A similar argument goes for determining the threshold marginal cost separating the firms that choose to enter with a merger from those that built their own plant abroad. For higher marginal cost values firms would prefer to enter by means of a merger, but the firms with lowest marginal cost find it more profitable to enter by greenfield FDI. Let's call $a_{G}$ the marginal cost cutoff where $f_{G}\left(a_{G}\right)=f_{M}\left(a_{G}\right)$. Substituting for the value functions and profits yields

$$
a_{G}^{1-\sigma}=\frac{F_{G}-F_{M}}{1-\psi z^{1-\sigma}} \frac{\gamma}{\delta P^{\sigma-1} C} .
$$

The formal derivation of all marginal cost cutoffs is provided in the appendix.

I solve for an equilibrium where

$$
0<a_{G}<a_{M}<a_{E}<a_{L}<\bar{a}
$$


holds. As I show in the appendix, in addition to (5) and (6), the following conditions must be satisfied for (13) to hold:

$$
\begin{gathered}
\frac{F_{L}}{1-(1-\psi) z^{1-\sigma} \varepsilon}<\frac{F_{E}}{\theta} . \\
\frac{F_{E}}{\theta}<\frac{F_{M}-F_{E}}{\psi z^{1-\sigma}-\theta} . \\
\frac{F_{G}-F_{M}}{1-\psi z^{1-\sigma}}>\frac{F_{M}-F_{E}}{\psi z^{1-\sigma}-\theta} .
\end{gathered}
$$

Condition (14) is similar to the one in Melitz (2003) ensuring that the more productive firms self-select into becoming exporters. At an intuitive level, it is reasonable to assume that a firm needs to pay a higher fixed cost for entering a foreign market than for entering its local market. Inequality (15) is more restrictive than $F_{M}>F_{E}$ in (5). $F_{M}$ has to be sufficiently larger than $F_{E}$. This is a reasonable assumption, meaning that it is significantly more costly to negotiate a merger than to enter the foreign market as an exporter. Condition (16) says that $F_{G}$ has to be sufficiently larger than $F_{M}$, or in other words, the cost to build a plant abroad must be sufficiently higher than the cost of negotiating a merger.

\subsection{The Incentive to Develop a Product}

To determine the incentive of firms to develop varieties, the benefit of innovating a product must be equal to the cost. The cost is $F_{I}$ labor units. The expected benefit is a bit more involving to describe.

First, upon drawing an unfavorable marginal cost $a>a_{L}$, the firm becomes a takeover target with a probability $\epsilon$ and gains a share $1-\psi$ from the proceeds of the merger. Second, given the firm draws a marginal cost low enough to enter its local market $a<a_{L}$, there is the expected benefit of selling there after paying the fixed cost to enter $F_{L}$. Third, for a marginal cost within the range $a \in\left(a_{M}, a_{E}\right)$, in addition to selling in its local market, the firm pays a fixed cost $F_{E}$ and starts exporting. Fourth, for a marginal cost within the range $a \in\left(a_{G}, a_{M}\right)$, the firm pays the fixed cost $F_{M}$ and merges with a foreign failing firm, obtaining in the process a share $\psi$ from the gains of the merger. Lastly, for a marginal cost $a \in\left(0, a_{G}\right)$, the firm pays a fixed cost $F_{G}$ and builds a plant abroad. The benefits are summarized on the right-hand side of the equation below:

$$
\begin{aligned}
F_{I}= & \int_{a_{L}}^{\bar{a}} v_{F} g(a) d a+\int_{0}^{a_{L}}\left(v_{L}(a)-F_{L}\right) g(a) d a+\int_{a_{M}}^{a_{E}}\left(\theta v_{L}(a)-F_{E}\right) g(a) d a \\
& +\int_{a_{G}}^{a_{M}}\left(\psi z^{1-\sigma} v_{L}(a)-F_{M}\right) g(a) d a+\int_{0}^{a_{G}}\left(v_{L}(a)-F_{G}\right) g(a) d a .
\end{aligned}
$$

The first integral represents the gain from a merger to a failing firm taking also into consideration the likelihood that the firm will draw a marginal cost within that range. The second integral shows the benefit from selling in the local market minus costs for entering it. The third, fourth and fifth integrals describe the benefits from entering the foreign market (net of fixed costs) depending on the firm's chosen mode of entry. After substituting for $\epsilon$ and 
using $\int_{a_{L}}^{\bar{a}} g\left(a_{f}\right) d a_{f}=1-G\left(a_{L}\right)$, the first integral can be rewritten

$$
\int_{a_{L}}^{\bar{a}} \epsilon(1-\psi) z^{1-\sigma} E\left[v_{L}(a)\right] g\left(a_{f}\right) d a_{f}=\left(G\left(a_{M}\right)-G\left(a_{G}\right)\right)(1-\psi) z^{1-\sigma} E\left[v_{L}(a)\right]
$$

I use $\left(G\left(a_{M}\right)-G\left(a_{G}\right)\right) E\left[v_{L}(a)\right]=\int_{a_{G}}^{a_{M}} v_{L}(a) g(a) d a$, which allows me to rewrite it further as $\int_{a_{G}}^{a_{M}}(1-\psi) z^{1-\sigma} v_{L}(a) g(a) d a$. I can therefore rewrite my original incentives to enter equation after combining the first and fourth integrals as

$$
\begin{aligned}
F_{I}= & \int_{0}^{a_{L}}\left(v_{L}(a)-F_{L}\right) g(a) d a+\int_{a_{M}}^{a_{E}}\left(\theta v_{L}(a)-F_{E}\right) g(a) d a \\
& +\int_{a_{G}}^{a_{M}}\left(z^{1-\sigma} v_{L}(a)-F_{M}\right) g(a) d a+\int_{0}^{a_{G}}\left(v_{L}(a)-F_{G}\right) g(a) d a .
\end{aligned}
$$

I group the fixed costs on the left-hand side, divide both sides by $G\left(a_{L}\right)$ and define

$$
F_{x} \equiv \frac{F_{I}}{G\left(a_{L}\right)}+F_{L}+F_{E} \frac{G\left(a_{E}\right)-G\left(a_{M}\right)}{G\left(a_{L}\right)}+F_{M} \frac{G\left(a_{M}\right)-G\left(a_{G}\right)}{G\left(a_{L}\right)}+F_{G} \frac{G\left(a_{G}\right)}{G\left(a_{L}\right)}
$$

I then substitute for $v_{L}(a)$ from (3), for profits from (2) and define

$$
\begin{aligned}
\Delta \equiv & \int_{0}^{a_{L}} a^{1-\sigma} \frac{g(a)}{G\left(a_{L}\right)} d a+\theta \int_{a_{M}}^{a_{E}} a^{1-\sigma} \frac{g(a)}{G\left(a_{L}\right)} d a \\
& +z^{1-\sigma} \int_{a_{G}}^{a_{M}} a^{1-\sigma} \frac{g(a)}{G\left(a_{L}\right)} d a+\int_{0}^{a_{G}} a^{1-\sigma} \frac{g(a)}{G\left(a_{L}\right)} d a,
\end{aligned}
$$

to obtain

$$
F_{x}=\frac{\delta P^{\sigma-1} C}{\gamma} \Delta
$$

This is the equation defining the incentive to develop a product. The left-hand side can be seen as the cost of developing a variety and the right-hand side as the benefit.

\subsection{Solving for the Aggregate Price Index}

I continue with finding an expression for the aggregate price index within a country $P$, which satisfies $P^{1-\sigma}=\int_{0}^{m^{c}} p(\omega)^{1-\sigma} d \omega$.

$$
\begin{aligned}
P^{1-\sigma}= & \int_{0}^{a_{L}} p_{L}(a)^{1-\sigma} m \frac{g(a)}{G\left(a_{L}\right)} d a+\int_{a_{M}}^{a_{E}} p_{E}(a)^{1-\sigma} m \frac{g(a)}{G\left(a_{L}\right)} d a \\
& +\int_{a_{G}}^{a_{M}} p_{L}\left(a^{\prime}\right)^{1-\sigma} m \frac{g\left(a_{h}\right)}{G\left(a_{L}\right)} d a_{h}+\int_{0}^{a_{G}} p_{L}(a)^{1-\sigma} m \frac{g(a)}{G\left(a_{L}\right)} d a .
\end{aligned}
$$

In the equation above $g(a) / G\left(a_{L}\right)$ is the density function conditional on entry. The first integral denotes the prices of all local originating firms with a productivity $a \in\left(0, a_{L}\right)$. Foreign originating firms with productivity $a \in\left(a_{M}, a_{E}\right)$ export to home and sell at $p_{E}(a)$. Their contribution to the price index is captured by the second integral. The next integral 
describes the prices of all foreign firms that have merged with a home failing firm. Prices charged by those firms are based on the marginal cost of the restructured plant $a^{\prime}$. Line four describes the contribution to the price index of foreign firms that have a subsidiary at home. Substituting for prices, rearranging and then substituting for $\Delta$ yields:

$$
P^{1-\sigma}=m\left(\frac{\sigma}{\sigma-1}\right)^{1-\sigma} \Delta .
$$

\subsection{Labor Market Clearing}

Labor is inelastically supplied and employed either for payment of the fixed costs, a total of $L_{I}$, or in the production sector, a total of $L_{P}$. Total labor supply can be expressed as $L=L_{P}+L_{I}$. Each worker is endowed with one unit of labor and receives a wage $w=1$ per unit of labor supplied. Labor markets are perfectly competitive and there is no unemployment.

Total workforce in production is given by the sum of labor producing for the local market and labor producing for the foreign market. For brevity, I write $a(\omega) x_{L}(\omega)$ as $a x_{L}$. To produce a variety for the local market, a firm needs $a x_{L}$ units of labor. To produce a variety for the export market, a firm needs $\tau a x_{E}$ units of labor. Let $x^{\prime}(\omega)$ be demand for a locally produced product with marginal cost $a^{\prime}(\omega)$. I will for brevity write this demand as $x^{\prime}$. Labor involved in production is

$$
L_{P}=m\left(\begin{array}{c}
\int_{0}^{a_{L}} a x_{L} \frac{g(a)}{G\left(a_{L}\right)} d a+\int_{a_{M}}^{a_{E}} \tau a x_{E} \frac{g(a)}{G\left(a_{L}\right)} d a \\
+\int_{a_{G}}^{a_{M}} a^{\prime} x^{\prime} \frac{g(a)}{G\left(a_{L}\right)} d a+\int_{0}^{a_{G}} a x_{L} \frac{g(a)}{G\left(a_{L}\right)} d a
\end{array}\right) .
$$

The first integral expresses what is produced by all non-failing firms for the local market. The second integral takes into consideration what is produced for exporting. The third integral takes into consideration what is produced by the formerly failing local firms that were taken over by a foreign firm. The fourth integral takes into consideration the production of subsidiaries of foreign firms. I substitute for $x_{L}, x_{E}, x^{\prime}$ and for $\Delta$ to obtain:

$$
L_{P}=\frac{\sigma-1}{\sigma} C .
$$

The full employment condition $L=L_{P}+L_{I}$ implies that:

$$
C=L+\frac{C}{\sigma}-L_{I}
$$

Aggregate income equals aggregate labor income $L$ plus aggregate income from profits $C / \sigma$, minus wages paid for labor used for the fixed costs $L_{I}$. I show in the appendix that $C / \sigma$ is aggregate income from profits.

I move on to express labor dedicated to the fixed costs firms have to pay. The labor dedicated to discovering a new product is $F_{I}$. The mass of firms that discover a product is $\dot{m} / G\left(a_{L}\right)$. Total labor cost for the creation of new products is therefore $\dot{m} F_{I} / G\left(a_{L}\right)$. Of all firms that have discovered a product, of mass $\dot{m} / G\left(a_{L}\right)$, only a fraction $\int_{0}^{a_{L}} g(a) d a=G\left(a_{L}\right)$ enter the local market and are productive enough to pay $F_{L}$, hence the total labor cost to 
the economy from entering the local market is $\dot{m} F_{L} G\left(a_{L}\right) / G\left(a_{L}\right)$. Again, of all firms that have discovered a product only a fraction enter the foreign market and pay the $F_{E}$ fixed cost. This fraction is $\int_{a_{M}}^{a_{E}} g(a) d a=G\left(a_{E}\right)-G\left(a_{M}\right)$. Hence the cost paid by those firms is $\dot{m} F_{E}\left(G\left(a_{E}\right)-G\left(a_{M}\right)\right) / G\left(a_{L}\right)$. A fraction $G\left(a_{M}\right)-G\left(a_{G}\right)$ of all firms that have entered pay the fixed cost to take over a foreign firm $\dot{m} F_{M}\left(G\left(a_{M}\right)-G\left(a_{G}\right)\right) / G\left(a_{L}\right)$. A fraction $G\left(a_{G}\right)$ pay the fixed cost to invest in a foreign subsidiary $\dot{m} F_{G} G\left(a_{G}\right) / G\left(a_{L}\right)$. The total amount of labor busy with activities related to the fixed costs is therefore:

$$
L_{I}=\dot{m} \frac{F_{I}}{G\left(a_{L}\right)}+\dot{m} F_{L}+\dot{m} F_{E} \frac{G\left(a_{E}\right)-G\left(a_{M}\right)}{G\left(a_{L}\right)}+\dot{m} F_{M} \frac{G\left(a_{M}\right)-G\left(a_{G}\right)}{G\left(a_{L}\right)}+\dot{m} F_{G} \frac{G\left(a_{G}\right)}{G\left(a_{L}\right)} .
$$

From the definition of $F_{x}$ it follows that $L_{I}=\dot{m} F_{x}$. Keeping in mind that the inflow of varieties equals the outflow $\dot{m}=\gamma m$ it follows that

$$
L_{I}=\gamma m F_{x}
$$

\section{Solving the Model}

I proceed with finding $a_{L}$. I substitute in (8) for the price index from (19) and obtain:

$$
\frac{\Delta}{a_{L}^{1-\sigma}} \frac{F_{L}}{1-(1-\psi) z^{1-\sigma} \varepsilon}=\frac{1}{m \gamma} \frac{C}{\sigma} .
$$

In the incentive for product creation condition (18), I substitute for the the price index from (19) and obtain

$$
F_{x}=\frac{1}{m \gamma} \frac{C}{\sigma}
$$

Next, using the definition of $\Delta$ and solving for the integrals, I can write $\Delta$ as a function of $a_{L}$

$$
\Delta \equiv a_{L}^{1-\sigma} \eta q_{1}\left(a_{L}\right)
$$

where $q_{1}()$ is a function of $a_{L}$ defined in the appendix. I assume that $k>\sigma-1$ to guarantee that the integrals converge and $\Delta$ is finite. Combining (22) and (23) yields $F_{x}=\frac{\Delta}{a_{L}^{1-\sigma}} \frac{F_{L}}{1-(1-\psi) z^{1-\sigma} \varepsilon}$. I substitute for $\Delta$ from $(24)$ to obtain $F_{x}=\frac{\eta q_{1}\left(a_{L}\right) F_{L}}{1-(1-\psi) z^{1-\sigma \varepsilon}}$. Further, from (17), substituting for the cumulative distribution functions yields a second expression for $F_{x}=q_{2}\left(a_{L}\right)$, where $q_{2}()$ is a function of $a_{L}$ defined in the appendix. Combining the two expressions for $F_{x}$ gives an equation, which I can solve to obtain a solution for $a_{L}$ :

$$
q_{2}\left(a_{L}\right)=q_{1}\left(a_{L}\right) \frac{\eta F_{L}}{1-(1-\psi) z^{1-\sigma} \varepsilon} .
$$

I can substitute the expression for $a_{L}$, which solves (25) into the definition of $\varepsilon(9)$ and find $\varepsilon$. Using $\varepsilon$ in (25) would give me $a_{L}$. Given $a_{L}$, I know $\Delta$ from (24), $a_{E}, a_{G}$ and $a_{M}$ from (8), (10), (11) and (12).

To find $C$, I substitute for $L_{I}$ from (21) and for $C / \sigma$ from (23) in (20), and obtain $C=L$. 
What remains is to find $m$. I substitute for $C=L$ and for $F_{x}=\frac{\eta q_{1}\left(a_{L}\right) F_{L}}{1-(1-\psi) z^{1-\sigma_{\varepsilon}}}$ into (23) to obtain

$$
m=\frac{1-(1-\psi) z^{1-\sigma} \varepsilon}{\eta q_{1}\left(a_{L}\right) F_{L}} \frac{L}{\gamma \sigma} .
$$

This completes the solution of the model.

\section{Results}

I first find the share of greenfield FDI in total FDI. Firms are born and make a decision about which markets to enter and how. There is a constant flow of resources towards M\&A and greenfield activity. The resources dedicated to M\&A are $F_{M} \dot{m}\left(G\left(a_{M}\right)-G\left(a_{G}\right)\right) / G\left(a_{L}\right)$, where $\left(G\left(a_{M}\right)-G\left(a_{G}\right)\right) / G\left(a_{L}\right)$ is the share of all local entrants $\dot{m}$ engaged in M\&A and $F_{M}$ is how much each firm that invests pays for a merger. Similarly, the total value of greenfield FDI is $F_{G} \dot{m} G\left(a_{G}\right) / G\left(a_{L}\right)$, where $G\left(a_{G}\right) / G\left(a_{L}\right)$ is the share of all local entrants $\dot{m}$ that choose to build a plant abroad and $F_{G}$ is the investment made by each of those firms. The share of greenfield investment, denoted by $\Omega$, is measured by greenfield FDI value divided by the sum of greenfield and M\&A value:

$$
\Omega \equiv \frac{F_{G} G\left(a_{G}\right)}{F_{G} G\left(a_{G}\right)+F_{M}\left(G\left(a_{M}\right)-G\left(a_{G}\right)\right)} .
$$

Dividing the numerator and denominator by $G\left(a_{L}\right)$ results in an expression that depends on $\left(\frac{a_{M}}{a_{L}}\right)^{k}$ and $\left(\frac{a_{G}}{a_{L}}\right)^{k}$. I show in the appendix that $\left(\frac{a_{M}}{a_{L}}\right)^{k}$ responds more strongly to trade liberalization than $\left(\frac{a_{G}}{a_{L}}\right)^{k}$ due to the fact that the former is directly affected by variable costs to trade. From the group of newly entering potential FDI firms it is only M\&A firms that choose to become exporters instead in a world with lower $\tau$. The value of greenfield FDI can both decrease or increase but the overall decrease in total FDI comes mostly at the expense of M\&A firms, thus leading to their lower share in total FDI $\Omega \downarrow$.

Proposition 1 Bilateral trade liberalization $\theta \uparrow$ leads to a higher share of greenfield FDI in total FDI $\Omega \uparrow$.

Empirical evidence in Nocke and Yeaple (2008) suggests that greater geographical proximity increases the share of greenfield investment in total FDI. While Nocke and Yeaple (2008) show this result assuming that greater proximity means lower fixed costs for building a factory abroad (their model does not have variable costs to trade), I am able to show the same result in a model with variable costs to trade. It is more natural to think of geographical proximity as lower transportation costs rather than fixed costs of entry.

In order to have a complete picture of the model and show how the remaining endogenous variables move as a result of trade liberalization I solve the model numerically. 


\subsection{Numerical solution}

In this subsection I look for the effects of trade liberalization on the marginal cost cutoffs, on the share of firms that export denoted by $\chi \equiv\left(G\left(a_{E}\right)-G\left(a_{M}\right)\right) / G\left(a_{L}\right)$ and on total FDI. In order to obtain the value of total FDI, I add the values of M\&A and greenfield investments

$$
\digamma \equiv \frac{F_{M} G\left(a_{M}\right)+\left(F_{G}-F_{M}\right) G\left(a_{G}\right)}{G\left(a_{L}\right)} .
$$

For the calculation of those it is not enough to know the sign of $\frac{\partial \varepsilon}{\partial \theta}$ but also its magnitude relative to $\varepsilon$. The expressions become quickly non-tractable, which calls for the numerical solution.

In my computer simulation, I use the following parameter values: $\alpha=0.714, k=3.735$, $z=1.1, \psi=0.5, \bar{a}=10, F_{I}=5, F_{L}=1, F_{E}=1.5, F_{M}=4$, and $F_{G}=80$. The rate of substitution between products is set at $\alpha=0.714$. This choice results in an elasticity of substitution of $\sigma=3.49$, within the bounds of the estimates in Broda and Weinstein (2006) and a 40\% markup, within range of the evidence presented in Basu (1996) and Norrbin (1993). Eaton, Kortum and Kramarz (2008) use data on exports and domestic sales by French firms and find that $k /(\sigma-1)=1.5$. To match this evidence, given my choice of $\sigma$, I set the parameter of the Pareto distribution at $k=3.735$. The parameter determining the productivity of the restructured foreign plant after a merger relative to the productivity of the parent firm, denoted by $z$, has to be larger than one. In combination with the parameter determining the bargaining power of the merging firms $\psi$, I set them so that $\theta<\psi z^{1-\sigma}<1$ (inequality (6)) holds.

The maximum marginal cost a firm can draw, $\bar{a}$, is a scale parameter and I set it equal to 10. The specific choice of $\bar{a}$ is not important for the results of the model. To be precise, $\bar{a}^{k}$ is the scale parameter. An increase in $\bar{a}^{k}$, accompanied by a proportionate increase in fixed costs would result in higher marginal cost cutoff values, but would not change variables like $\chi, \Omega$ etc. Particular fixed cost values are chosen according to (14), (15), (16), (5), (7), also making sure that after solving for $a_{L}$, I am left with $a_{L}<\bar{a}$. The fixed cost for entering the local market $F_{L}$ is smaller than the one for entering the foreign market as an exporter $F_{E}$, which in turn is smaller than the fixed cost for initiating a merger $F_{M}$. The most costly mode of entry abroad is by building a plant $F_{G}$. I evaluate the model for a change in $\tau$ from 1.7 to 1.3 (or $\theta$ changing from 0.26 to 0.51 ). At low values of $\tau$ there would be no FDI and all firms would prefer to export. The results from solving the model numerically are shown in Table 1.

\begin{tabular}{l|lllllllll}
$\tau$ & $a_{L}$ & $a_{E}$ & $a_{M}$ & $a_{G}$ & $\chi$ & $\varepsilon$ & $\epsilon$ & $\Omega$ & $\digamma$ \\
\hline 1.7 & 8.46 & 4.74 & 3.98 & 1.213 & 0.05 & 1.05 & 0.068 & 0.19 & 0.293 \\
1.5 & 8.57 & 5.33 & 3.33 & 1.203 & 0.13 & 0.86 & 0.037 & 0.31 & 0.167 \\
1.3 & 8.91 & 5.95 & 1.59 & 1.165 & 0.21 & 0.21 & 0.002 & 0.89 & 0.044
\end{tabular}

Table 1. The Effects of Lower Variable Costs to Trade $(\tau \downarrow)$

The marginal cost cutoff for firms entering their home market $a_{L}$ increases as a result of trade liberalization. It is interesting to note that this effect on $a_{L}$ is the opposite to the one found in Melitz (2003). The decision of a firm to enter or exit its local market is based not 
only on its ability to pay the entry fixed cost but also on its exit value $v_{F}$ when becoming a potential takeover target, which equals the probability of a merger times the expected gain. Lower $\tau$ leads to an increased competition from a larger number of exporters $(\chi \uparrow)$, thus decreasing $a_{L}$ as in Melitz (2003). Lower $\tau$ leads however also to a lower probability of being taken over $\epsilon \downarrow$ and an altogether lower expected gain from choosing to become a takeover target $\varepsilon \downarrow$. This makes exit less attractive and more firms prefer to enter the local market, thus increasing $a_{L}$. The second channel is in this case stronger leading to the higher $a_{L}$.

By looking at the column for the percentage of firms that export $\chi$, one can see that the majority of firms are non-exporters in equilibrium. This is what Bernard et. al. (2003) find in their study of 200,000 US manufacturing plants, where only $21 \%$ report exporting. Intuitively, as exporting becomes more profitable $\tau \downarrow$ the share of firms engaging in exporting increases $\chi \uparrow$.

As previously shown lower transportation costs $\tau \downarrow$ lead to a greater share of greenfield FDI in total FDI $\Omega \uparrow$, where $\Omega=19 \%$ at $\tau=1.7$ and $\Omega=89 \%$ at $\tau=1.3$. For intermediate values of $\tau$ these number is consistent with the data reported in Head and Ries (2008), where greenfield FDI is roughly one third of total FDI. The total amount of FDI decreases $\digamma \downarrow$ as predicted by the proximity concentration trade-off.

\section{Conclusion}

I develop a model of international trade and foreign direct investment, where FDI consists of cross-border mergers and greenfield FDI. I abstract from any strategic motives for a merger, since I work with firms in a monopolistically competitive environment. The incentive for firms to merge comes from the transfer of technology and managerial know-how. Exporters are more productive than non-exporters. Firms that engage in FDI are more productive than exporters and within the group of FDI firms, it is the most productive ones that become greenfield investors.

The contribution of the paper is to build a model where greenfield FDI and cross-border M\&A flow both ways from Home to Foreign and from Foreign to Home. In addition, it generates the result that lower variable costs to trade (which can be interpreted as greater proximity to the foreign market) increase the share of greenfield FDI in total FDI. Nocke and Yeaple (2008) obtain this result in an asymmetric country setting, where greenfield FDI flows only from the richer to the poorer country and by assuming that country proximity translates into lower fixed cost for investing abroad.

\section{References}

[1] Aw, Bee Yan, Sakkyun Chung and Mark J. Roberts (2000), "Productivity and Turnover in the Export Market: Micro-Level Evidence from the Republic of Korea and Taiwan (China)," World Bank Economic Review, 14, 65-90.

[2] Basu, Susanto (1996), "Procyclical Productivity: Increasing Returns or Cyclical Utilization," Quarterly Journal of Economics, 111, 709-751. 
[3] Bernard, Andrew B., and J. Bradford Jensen (1999), "Exceptional Exporter Performance: Cause, Effect or Both?," Journal of International Economics, 47, 1-25.

[4] Bernard, Andrew B., Jonathan Eaton, J. Bradford Jensen and Samuel Kortum (2003), "Plants and Productivity in International Trade," American Economic Review, 93, $1268-1290$.

[5] Binmore, Kenneth G., Ariel Rubinstein and Asher Wolinsky (1986), "The Nash Bargaining Solution in Economic Modelling," Rand Journal of Economics, 17, 176-188.

[6] Bloom, Nicholas and John Van Reenen (2010), "Why Do Management Practices Differ across Firms and Countries?," Journal of Economic Perspectives, 24, 203-224.

[7] Breinlich, Holger (2008), "Trade Liberalization and Industrial Restructuring through Mergers and Acquisitions," Journal of International Economics, 76, 254-266.

[8] Broda, Christian and David E. Weinstein (2006), "Globalization and the Gains from Variety." Quarterly Journal of Economics, 121, 541-585.

[9] Clerides, Sofronis K., Saul Lach and James R. Tybout (1998), "Is Learning by Exporting Important? Microdynamic Evidence from Colombia, Mexico and Morocco," Quarterly Journal of Economics, 113, 903-947.

[10] Conyon, Martin J., Sourafel Girma, Steve Thompson and Peter W. Wright (2002), "The Productivity and Wage Effects of Foreign Acquisition in the United Kingdom," Journal of Industrial Economics, 50, 85-102.

[11] Del Gatto, Massimo, Giordano Mion and Gianmarco I.P. Ottaviano (2006), "Trade Integration, Firm Selection and the Costs of Non-Europe," mimeo, University of Bologna.

[12] Eaton, Jonathan, Samuel Kortum, and Francis Kramarz (2008), "An Anatomy of International Trade: Evidence from French Firms." NBER Working Paper No.146110.

[13] Girma, Sourafel, Richard Kneller and Mauro Pisu (2005) "Exports versus FDI: an Empirical Test," Review of World Economics, 141, 193-218.

[14] Gugler, Klaus, Dennis C. Mueller, B.Burcin Yurtoglu and Christine Zulehner (2003), "The Effects of Mergers: An International Comparison," International Journal of Industrial Organization, 21, 625-653.

[15] Head, Keith and John Ries (2008), "FDI as an Outcome of the Market for Corporate Control: theory and Evidence," Journal of International Economics, 74, 2-20.

[16] Helpman, Elhanan (2006), "Trade, FDI and the Organization of Firms," Journal of Economic Literature, 44, 589-630.

[17] Helpman, Elhanan, Mark J. Melitz and Stephen R. Yeaple (2004), "Export versus FDI with Heterogeneous Firms," American Economic Review, 94, 300-316. 
[18] Jensen, Michael C. (1988), "Takeovers: Their Causes and Consequences" Journal of Economic Perspectives, 2, 21-48.

[19] Mandelker, Gershon (1974), "Risk and Return: The case of Merging Firms," Journal of Financial Economics, 1, 303-335.

[20] Melitz, Marc J. (2003), "The Impact of Trade on Intra-Industry Reallocations and Aggregate Industry Productivity," Econometrica, 71, 1695-1725.

[21] Neary, Peter J. (2009), "Trade Costs and Foreign Direct Investment," International Review of Economics and Finance, 18, 207-218.

[22] Nocke, Volker and Stephen Yeaple (2007), "Cross-border Mergers and Acquisitions vs. Greenfield Foreign Direct Investment: The Role of Firm Heterogeneity," Journal of International Economics, 72, 336-365.

[23] Nocke, Volker and Stephen Yeaple (2008), "An Assignment Theory of Foreign Direct Investment," Review of Economic Studies, 75, 529-557.

[24] Norbäck, Pehr-Johan and Lars Persson (2007), "Investment Liberalization-Why a Restrictive Cross-Border Merger Policy Can Be Counterproductive," Journal of International Economics, 72, 366-380.

[25] Norbäck, Pehr-Johan and Lars Persson (2008), "Globalization and Profitability of CrossBorder Mergers and Acquisitions," Economic Theory, 35, 241-266.

[26] Norrbin, Stefan C. (1993), "The Relationship between Price and Marginal Cost in US Industry: A Contradiction," Journal of Political Economy, 101, 1149-1164.

[27] Raff, Horst, Michael Ryan and Frank Stähler (2011), "Firm Productivity and the Foreign-Market Entry Decision," University of Kiel, mimeo.

[28] Röller, Lars-Hendrik, Johan Stennek and Frank Verboven (2006), "Efficiency Gains From Mergers," Chapter in "European Merger Control: Do We Need an Efficiency Defence".

[29] UNCTAD (2000): "World Investment Report: Cross-Border Mergers and Acquisitions and Development," New York and Geneva, United Nations.

[30] Werden, Gregory J. (1996), "A robust Test for Consumer Welfare Enhancing Mergers Among Sellers of differentiated Products," Journal of Industrial Economics, 44, 409413. 


\section{Appendix}

\section{The Marginal Cost Cutoffs}

In this section, I find the marginal cost cutoffs. To solve for $a_{L}$ I use $f_{L}\left(a_{L}\right)=v_{L}\left(a_{L}\right)-F_{L}=$ $v_{F}$ :

$$
v_{L}\left(a_{L}\right)-F_{L}=\epsilon(1-\psi) z^{1-\sigma} E\left[v_{L}\left(a_{h}\right)\right]
$$

I substitute for $v_{L}\left(a_{L}\right)$ using (3) and for profits using (2):

$$
\frac{\delta a_{L}^{1-\sigma} P^{\sigma-1} C}{\gamma}-F_{L}=\epsilon(1-\psi) z^{1-\sigma} \frac{\delta E\left[a_{h}^{1-\sigma}\right] P^{\sigma-1} C}{\gamma} .
$$

I can write

$$
\begin{aligned}
\epsilon E\left[a_{h}^{1-\sigma}\right] & =\frac{G\left(a_{M}\right)-G\left(a_{G}\right)}{1-G\left(a_{L}\right)} \int_{a_{G}}^{a_{M}} a_{h}^{1-\sigma} \frac{g\left(a_{h}\right)}{G\left(a_{M}\right)-G\left(a_{G}\right)} d a_{h} \\
& =\int_{a_{G}}^{a_{M}} a_{h}^{1-\sigma} \frac{k a_{h}^{k-1} / \bar{a}^{k}}{1-\left(a_{L} / \bar{a}\right)^{k}} d a_{h} \\
& =\frac{k}{k-\sigma+1} \frac{1}{\bar{a}^{k}-a_{L}^{k}}\left[a_{h}^{k-\sigma+1}\right]_{a_{G}}^{a_{M}} \\
& =\frac{k}{k-\sigma+1} \frac{a_{M}^{k-\sigma+1}-a_{G}^{k-\sigma+1}}{\bar{a}^{k}-1} \\
& =a_{L}^{1-\sigma} \varepsilon,
\end{aligned}
$$

where for brevity

$$
\varepsilon \equiv \frac{k}{k-\sigma+1} \frac{\left(a_{M} / a_{L}\right)^{k-\sigma+1}-\left(a_{G} / a_{L}\right)^{k-\sigma+1}}{\left(\bar{a} / a_{L}\right)^{k}-1} .
$$

Using this I can go back to the equation for $a_{L}$ and rearrange terms:

$$
a_{L}^{1-\sigma}=\frac{F_{L}}{1-(1-\psi) z^{1-\sigma} \varepsilon} \frac{\gamma}{\delta P^{\sigma-1} C} .
$$

This is equation (8) in the main text.

To solve for $a_{E}$, I use $f_{E}\left(a_{E}\right)=\theta v_{L}\left(a_{E}\right)-F_{E}=0$ to obtain

$$
\theta v_{L}\left(a_{E}\right)=F_{E}
$$

I substitute for $v_{L}\left(a_{E}\right)$ from (3) and for profits using (2) to obtain

$$
\frac{\delta a_{E}^{1-\sigma} P^{\sigma-1} C}{\gamma}=\frac{F_{E}}{\theta} .
$$

Rearranging terms yields equation (10) in the main text:

$$
a_{E}^{1-\sigma}=\frac{F_{E}}{\theta} \frac{\gamma}{\delta P^{\sigma-1} C}
$$


To solve for $a_{M}$, I use $f_{M}\left(a_{M}\right)=f_{E}\left(a_{M}\right)$ :

$$
\begin{aligned}
\psi z^{1-\sigma} v_{L}\left(a_{M}\right)-F_{M} & =\theta v_{L}\left(a_{M}\right)-F_{E} \\
v_{L}\left(a_{M}\right) & =\frac{F_{M}-F_{E}}{\psi z^{1-\sigma}-\theta} .
\end{aligned}
$$

I substitute for $v_{L}$ using (3) and for profits using (2):

$$
\frac{\delta a_{M}^{1-\sigma} P^{\sigma-1} C}{\gamma}=\frac{F_{M}-F_{E}}{\psi z^{1-\sigma}-\theta} .
$$

Rearranging terms yields equation (11) in the main text:

$$
a_{M}^{1-\sigma}=\frac{F_{M}-F_{E}}{\psi z^{1-\sigma}-\theta} \frac{\gamma}{\delta P^{\sigma-1} C} .
$$

To solve for $a_{G}$ I use $f_{G}\left(a_{G}\right)=f_{M}\left(a_{G}\right)$ :

$$
\begin{aligned}
\psi z^{1-\sigma} v_{L}\left(a_{G}\right)-F_{M} & =v_{L}\left(a_{G}\right)-F_{G} \\
v_{L}\left(a_{G}\right) & =\frac{F_{G}-F_{M}}{1-\psi z^{1-\sigma}} .
\end{aligned}
$$

I substitute for $v_{L}$ using (3) and for profits using (2):

$$
\frac{\delta a_{G}^{1-\sigma} P^{\sigma-1} C}{r-g}=\frac{F_{G}-F_{M}}{1-\psi z^{1-\sigma}} .
$$

Rearranging terms yields equation (12) in the main text:

$$
a_{G}^{1-\sigma}=\frac{F_{G}-F_{M}}{1-\psi z^{1-\sigma}} \frac{\gamma}{\delta P^{\sigma-1} C} .
$$

For (13) to hold, the following three conditions must be satisfied: First, for $a_{E}<a_{L}$ or $a_{L}^{1-\sigma}<a_{E}^{1-\sigma},(8)$ and (10) imply that

$$
\frac{F_{L}}{1-(1-\psi) z^{1-\sigma} \varepsilon}<\frac{F_{E}}{\theta} .
$$

This is condition (14) in the main text. Second, for $a_{M}<a_{E}$ or $a_{E}^{1-\sigma}<a_{M}^{1-\sigma},(10)$ and (11) imply that

$$
\frac{F_{E}}{\theta}<\frac{F_{M}-F_{E}}{\psi z^{1-\sigma}-\theta} .
$$

This is condition (15) in the main text. Third, for $a_{G}<a_{M}$ or $a_{M}^{1-\sigma}<a_{G}^{1-\sigma}$, (11) and (12) imply that

$$
\frac{F_{G}-F_{M}}{1-\psi z^{1-\sigma}}>\frac{F_{M}-F_{E}}{\psi z^{1-\sigma}-\theta} .
$$

This is condition (16) in the main text. 


\section{Labor Market Clearing}

I first calculate labor involved in production:

$$
L=m\left(\begin{array}{c}
\int_{0}^{a_{L}} a x_{L} \frac{g(a)}{G\left(a_{L}\right)} d a+\int_{a_{M}}^{a_{E}} \tau a x_{E} \frac{g(a)}{G\left(a_{L}\right)} d a \\
+\int_{a_{G}}^{a_{M}} a^{\prime} x^{\prime} \frac{g\left(a_{h}\right)}{G\left(a_{L}\right)} d a_{h}+\int_{0}^{a_{G}} a x_{L} \frac{g(a)}{G\left(a_{L}\right)} d a
\end{array}\right) .
$$

To produce a variety for the local market a firm needs to use $a x_{L}$ labor units. Using (1) yields $a x_{L}=a p_{L}(a)^{-\sigma} P^{\sigma-1} C$, where I have used aggregate consumption $C=c L$. I substitute for the optimal price $p_{L}(a)=\frac{\sigma}{\sigma-1} a$ to obtain $a x_{L}=a^{1-\sigma}\left(\frac{\sigma}{\sigma-1}\right)^{-\sigma} P^{\sigma-1} C$. For exporting, a firm produces with $\tau a x_{E}=\tau a p_{E}(a)^{-\sigma} P^{\sigma-1} C$ labor units, where I use (1) to substitute for demand. Substituting for $p_{E}(a)=\frac{\sigma}{\sigma-1} \tau a$ yields $\tau a x_{E}=\tau^{1-\sigma} a^{1-\sigma}\left(\frac{\sigma}{\sigma-1}\right)^{-\sigma} P^{\sigma-1} C=$ $\theta a^{1-\sigma}\left(\frac{\sigma}{\sigma-1}\right)^{-\sigma} P^{\sigma-1} C$, where I have used $\theta \equiv \tau^{1-\sigma}$. The local firms that were taken over by a foreign firm need $a^{\prime} x^{\prime}$ units of labor. Using (1) to substitute for demand yields $a^{\prime} x^{\prime}=a^{\prime} p_{L}\left(a^{\prime}\right)^{-\sigma} P^{\sigma-1} C$. I substitute for the optimal price $p_{L}\left(a^{\prime}\right)=\frac{\sigma}{\sigma-1} a^{\prime}$ to obtain $a^{\prime} x_{L}^{\prime}=\left(a^{\prime}\right)^{1-\sigma}\left(\frac{\sigma}{\sigma-1}\right)^{-\sigma} P^{\sigma-1} C=(z a)^{1-\sigma}\left(\frac{\sigma}{\sigma-1}\right)^{-\sigma} P^{\sigma-1} C$. Going back to the expression for $L_{P}$, I obtain

$$
\begin{aligned}
L_{P} & =m\left(\frac{\sigma}{\sigma-1}\right)^{-\sigma} P^{\sigma-1} C\left(\begin{array}{c}
\int_{0}^{a_{L}} a^{1-\sigma} \frac{g(a)}{G\left(a_{L}\right)} d a+\theta \int_{a_{M}}^{a_{E}} a^{1-\sigma} \frac{g(a)}{G\left(a_{L}\right)} d a \\
+z^{1-\sigma} \int_{a_{G}}^{a_{M}} a^{1-\sigma} \frac{g(a)}{G\left(a_{L}\right)} d a+\int_{0}^{a_{G}} a^{1-\sigma} \frac{g(a)}{G\left(a_{L}\right)} d a
\end{array}\right) \\
& =m\left(\frac{\sigma}{\sigma-1}\right)^{-\sigma} P^{\sigma-1} C \Delta .
\end{aligned}
$$

I substitute for $P^{1-\sigma}$ to obtain

$$
\begin{aligned}
L_{P} & =\frac{m\left(\frac{\sigma}{\sigma-1}\right)^{-\sigma} C \Delta}{m\left(\frac{\sigma}{\sigma-1}\right)^{1-\sigma} \Delta} \\
& =\frac{\sigma-1}{\sigma} C .
\end{aligned}
$$

The full employment condition $L=L_{P}+L_{I}$ implies that $L=\frac{\sigma-1}{\sigma} C+L_{I}$, which in turn leads to equation (20) in the main text

$$
C=L+\frac{C}{\sigma}-L_{I}
$$

To show that $C / \sigma$ is aggregate income from profits, I integrate over the profits of all companies originating from a country and denote that value as $\Lambda$ :

$$
\begin{aligned}
\Lambda \equiv & \int_{0}^{a_{L}} \pi_{L}(a) m \frac{g(a)}{G\left(a_{L}\right)} d a+\int_{a_{M}}^{a_{E}} \pi_{E}(a) m \frac{g(a)}{G\left(a_{L}\right)} d a \\
& +\int_{a_{G}}^{a_{M}} \pi_{L}\left(a^{\prime}\right) m \frac{g\left(a_{h}\right)}{G\left(a_{L}\right)} d a_{h}+\int_{0}^{a_{G}} \pi_{L}(a) m \frac{g(a)}{G\left(a_{L}\right)} d a \\
= & \delta P^{\sigma-1} C m\left(\begin{array}{c}
\int_{0}^{a_{L}} a^{1-\sigma} \frac{g(a)}{G\left(a_{L}\right)} d a+\theta \int_{a_{M}}^{a_{E}} a^{1-\sigma} \frac{g(a)}{G\left(a_{L}\right)} d a \\
+z^{1-\sigma} \int_{a_{G}}^{a_{M}} a_{h}^{1-\sigma} \frac{g\left(a_{h}\right)}{G\left(a_{L}\right)} d a_{h}+\int_{0}^{a_{G}} a^{1-\sigma} \frac{g(a)}{G\left(a_{L}\right)} d a
\end{array}\right) \\
= & \delta P^{\sigma-1} C m \Delta .
\end{aligned}
$$

Substituting for $P^{1-\sigma}$ yields $\Lambda=C / \sigma$. 


\section{Solving the Model}

Next I find an expression for $\Delta$ in one unknown $a_{L}$. Using the properties of the Pareto distribution

$$
\frac{g(a)}{G\left(a_{L}\right)}=\frac{\left(k a^{k-1} / \bar{a}^{k}\right)}{\left(a_{L}^{k} / \bar{a}^{k}\right)}=\frac{k a^{k-1}}{a_{L}^{k}},
$$

and the definition for $\Delta$ gives:

$$
\begin{aligned}
\Delta= & \int_{0}^{a_{L}} a^{1-\sigma} \frac{k a^{k-1}}{a_{L}^{k}} d a+\theta \int_{a_{M}}^{a_{E}} a^{1-\sigma} \frac{k a^{k-1}}{a_{L}^{k}} d a \\
& +z^{1-\sigma} \int_{a_{G}}^{a_{M}} a_{h}^{1-\sigma} \frac{k a_{h}^{k-1}}{a_{L}^{k}} d a_{h}+\int_{0}^{a_{G}} a^{1-\sigma} \frac{k a^{k-1}}{a_{L}^{k}} d a .
\end{aligned}
$$

The assumption that $k>\sigma-1$ guarantees that the integrals converge and $\Delta$ is finite. Lower values of $k$ would result in explosive profits for marginal costs close to zero. Using $\eta \equiv k /(k-\sigma+1)$ and solving the integrals yields

$$
\begin{aligned}
\Delta= & \frac{k}{k-\sigma+1}\left[a^{k-\sigma+1}\right]_{0}^{a_{L}} \frac{1}{a_{L}^{k}}+\theta \frac{k}{k-\sigma+1}\left[a^{k-\sigma+1}\right]_{a_{M}}^{a_{E}} \frac{1}{a_{L}^{k}} \\
& +z^{1-\sigma} \frac{k}{k-\sigma+1}\left[a^{k-\sigma+1}\right]_{a_{G}}^{a_{M}} \frac{1}{a_{L}^{k}}+\frac{k}{k-\sigma+1}\left[a^{k-\sigma+1}\right]_{0}^{a_{G}} \frac{1}{a_{L}^{k}} \\
= & \frac{k}{k-\sigma+1}\left(\frac{a_{L}^{k-\sigma+1}}{a_{L}^{k}}+\theta \frac{a_{E}^{k-\sigma+1}-a_{M}^{k-\sigma+1}}{a_{L}^{k}}+z^{1-\sigma} \frac{a_{M}^{k-\sigma+1}-a_{G}^{k-\sigma+1}}{a_{L}^{k}}+\frac{a_{G}^{k-\sigma+1}}{a_{L}^{k}}\right) \\
= & \frac{k}{k-\sigma+1} a_{L}^{1-\sigma}\left(\begin{array}{c}
1+\theta\left(\left(\frac{a_{E}}{a_{L}}\right)^{k-\sigma+1}-\left(\frac{a_{M}}{a_{L}}\right)^{k-\sigma+1}\right) \\
+z^{1-\sigma}\left(\left(\frac{a_{M}}{a_{L}}\right)^{k-\sigma+1}-\left(\frac{a_{G}}{a_{L}}\right)^{k-\sigma+1}\right)+\left(\frac{a_{G}}{a_{L}}\right)^{k-\sigma+1}
\end{array}\right)
\end{aligned}
$$

To find $\left(a_{E} / a_{L}\right)^{k-\sigma+1}$, I use (8) and (10):

$$
\begin{aligned}
\frac{a_{E}^{1-\sigma}}{a_{L}^{1-\sigma}} & =\frac{1-(1-\psi) z^{1-\sigma} \varepsilon}{\theta} \frac{F_{E}}{F_{L}} \\
\left(\frac{a_{E}}{a_{L}}\right)^{k-\sigma+1} & =\left(\frac{1-(1-\psi) z^{1-\sigma} \varepsilon}{\theta} \frac{F_{E}}{F_{L}}\right)^{\frac{k-\sigma+1}{1-\sigma}} .
\end{aligned}
$$

To find $\left(a_{M} / a_{L}\right)^{k-\sigma+1}$, I use (8) and (11):

$$
\begin{aligned}
\frac{a_{M}^{1-\sigma}}{a_{L}^{1-\sigma}} & =\frac{1-(1-\psi) z^{1-\sigma} \varepsilon}{\psi z^{1-\sigma}-\theta} \frac{F_{M}-F_{E}}{F_{L}} \\
\left(\frac{a_{M}}{a_{L}}\right)^{k-\sigma+1} & =\left(\frac{1-(1-\psi) z^{1-\sigma} \varepsilon}{\psi z^{1-\sigma}-\theta} \frac{F_{M}-F_{E}}{F_{L}}\right)^{\frac{k-\sigma+1}{1-\sigma}}
\end{aligned}
$$

To find $\left(a_{G} / a_{L}\right)^{k-\sigma+1}$, I use (8) and (12):

$$
\begin{aligned}
\frac{a_{G}^{1-\sigma}}{a_{L}^{1-\sigma}} & =\frac{1-(1-\psi) z^{1-\sigma} \varepsilon}{1-\psi z^{1-\sigma}} \frac{F_{G}-F_{M}}{F_{L}} \\
\left(\frac{a_{G}}{a_{L}}\right)^{k-\sigma+1} & =\left(\frac{1-(1-\psi) z^{1-\sigma} \varepsilon}{1-\psi z^{1-\sigma}} \frac{F_{G}-F_{M}}{F_{L}}\right)^{\frac{k-\sigma+1}{1-\sigma}} .
\end{aligned}
$$


I define for brevity $\beta \equiv k /(\sigma-1)$ and write $\frac{k-\sigma+1}{1-\sigma}=1-\frac{k}{1-\sigma}=1-\beta$. I substitute for the above three ratios of the threshold marginal costs into the expression for $\Delta$ to obtain

$$
\Delta \equiv a_{L}^{1-\sigma} \eta\left(\begin{array}{c}
1+\theta\left(\frac{1-(1-\psi) z^{1-\sigma} \varepsilon}{\theta} \frac{F_{E}}{F_{L}}\right)^{1-\beta}+\left(z^{1-\sigma}-\theta\right)\left(\frac{1-(1-\psi) z^{1-\sigma} \varepsilon}{\psi z^{1-\sigma}-\theta} \frac{F_{M}-F_{E}}{F_{L}}\right)^{1-\beta} \\
+\left(1-z^{1-\sigma}\right)\left(\frac{1-(1-\psi) z^{1-\sigma} \varepsilon}{1-\psi z^{1-\sigma}} \frac{F_{G}-F_{M}}{F_{L}}\right)^{1-\beta}
\end{array}\right) .
$$

This is equation (24) in the main text where $q_{1}()$ is the expression in brackets and is a function exogenous variables and $a_{L}$.

In (17) I substitute for the cumulative distribution functions

$$
\begin{aligned}
F_{x}= & \frac{F_{I}}{\left(a_{L} / \bar{a}\right)^{k}}+F_{L}+F_{E} \frac{\left(a_{E} / \bar{a}\right)^{k}-\left(a_{M} / \bar{a}\right)^{k}}{\left(a_{L} / \bar{a}\right)^{k}} \\
& +F_{M} \frac{\left(a_{M} / \bar{a}\right)^{k}-\left(a_{G} / \bar{a}\right)^{k}}{\left(a_{L} / \bar{a}\right)^{k}}+F_{G} \frac{\left(a_{G} / \bar{a}\right)^{k}}{\left(a_{L} / \bar{a}\right)^{k}} \\
= & F_{I}\left(\bar{a} / a_{L}\right)^{k}+F_{L}+F_{E}\left(\left(a_{E} / a_{L}\right)^{k}-\left(a_{M} / a_{L}\right)^{k}\right) \\
& +F_{M}\left(\left(a_{M} / a_{L}\right)^{k}-\left(a_{G} / a_{L}\right)^{k}\right)+F_{G}\left(a_{G} / a_{L}\right)^{k} \\
= & F_{I}\left(\bar{a} / a_{L}\right)^{k}+F_{L}+F_{E}\left(a_{E} / a_{L}\right)^{k} \\
& +\left(F_{M}-F_{E}\right)\left(a_{M} / a_{L}\right)^{k}+\left(F_{G}-F_{M}\right)\left(a_{G} / a_{L}\right)^{k} .
\end{aligned}
$$

From (8), (10), (11) and (12) I know that

$$
\begin{aligned}
\left(\frac{a_{E}}{a_{L}}\right)^{k} & =\left(\frac{1-(1-\psi) z^{1-\sigma} \varepsilon}{\theta} \frac{F_{E}}{F_{L}}\right)^{-\beta} \\
\left(\frac{a_{M}}{a_{L}}\right)^{k} & =\left(\frac{1-(1-\psi) z^{1-\sigma} \varepsilon}{\psi z^{1-\sigma}-\theta} \frac{F_{M}-F_{E}}{F_{L}}\right)^{-\beta} \\
\left(\frac{a_{G}}{a_{L}}\right)^{k} & =\left(\frac{1-(1-\psi) z^{1-\sigma} \varepsilon}{1-\psi z^{1-\sigma}} \frac{F_{G}-F_{M}}{F_{L}}\right)^{-\beta} .
\end{aligned}
$$

Substituting the above three ratios of the threshold marginal costs into the expression for $F_{x}$ yields an expression in $a_{L}$ and exogenous variables only, which I write for brevity as $F_{x}=q_{2}()$.

\section{Showing $\frac{\partial \Omega}{\partial \theta}>0$}

I use the definition of $\Omega$ and rewrite it as

$$
\Omega=\frac{F_{G} G}{F_{G} G+F_{M}(M-G)} .
$$

where for brevity $G \equiv\left(\frac{a_{G}}{a_{L}}\right)^{k}, M \equiv\left(\frac{a_{M}}{a_{L}}\right)^{k}$. Then

$$
\frac{\partial \Omega}{\partial \theta}=\frac{F_{G} \frac{\partial G}{\partial \theta}\left(F_{G} G+F_{M}(M-G)\right)-F_{G} G\left(F_{G} \frac{\partial G}{\partial \theta}+F_{M}\left(\frac{\partial M}{\partial \theta}-\frac{\partial G}{\partial \theta}\right)\right)}{\left(F_{G} G+F_{M}(M-G)\right)^{2}} .
$$


What matters for the sign of the above expression is the sign of the numerator. Simplifying the numerator yields $\frac{\partial G}{\partial \theta} M-\frac{\partial M}{\partial \theta} G$.

$$
\begin{aligned}
& \frac{\partial G}{\partial \theta} M=\beta \frac{(1-\psi) z^{1-\sigma}}{1-(1-\psi) z^{1-\sigma} \varepsilon} \frac{\partial \varepsilon}{\partial \theta} M G \\
& \frac{\partial M}{\partial \theta} G=\beta \frac{(1-\psi) z^{1-\sigma}}{1-(1-\psi) z^{1-\sigma} \varepsilon} \frac{\frac{\partial \varepsilon}{\partial \theta}\left(\psi z^{1-\sigma}-\theta\right)-\frac{1}{(1-\psi) z^{1-\sigma}}+\varepsilon}{\left(\psi z^{1-\sigma}-\theta\right)} M G .
\end{aligned}
$$

I divide $\frac{\partial G}{\partial \theta} M-\frac{\partial M}{\partial \theta} G$ by the common positive term $\beta \frac{(1-\psi) z^{1-\sigma}}{1-(1-\psi) z^{1-\sigma} \varepsilon} M G$ and obtain

$$
\frac{\partial \varepsilon}{\partial \theta}-\frac{\frac{\partial \varepsilon}{\partial \theta}\left(\psi z^{1-\sigma}-\theta\right)-\frac{1}{(1-\psi) z^{1-\sigma}}+\varepsilon}{\left(\psi z^{1-\sigma}-\theta\right)},
$$

which equals

$$
\frac{1-(1-\psi) z^{1-\sigma} \varepsilon}{(1-\psi) z^{1-\sigma}\left(\psi z^{1-\sigma}-\theta\right)}
$$

The above expression is greater than zero, therefore $\frac{\partial G}{\partial \theta} M-\frac{\partial M}{\partial \theta} G>0$ and $\frac{\partial \Omega}{\partial \theta}>0$. 